\title{
Structural Endpoints and Outcome Measures in Uveitis
}

\author{
Maximilian W.M. Wintergerst ${ }^{\mathrm{a}} \quad$ Xiaoxuan Liu $^{\mathrm{b}, \mathrm{c}, \mathrm{d}} \quad$ Jan H. Terheyden ${ }^{\mathrm{a}}$ \\ Dominika Pohlmann ${ }^{\mathrm{e}}$ Jeany Q. Li $^{\mathrm{a}}$ Giovanni Montesano $^{f}$ Giovanni Ometto $^{f}$ \\ Frank G. Holz ${ }^{a}$ David P. Crabb ${ }^{f}$ Uwe Pleyere Carsten Heinz ${ }^{g, h}$ \\ Alastair K. Denniston ${ }^{b}, c, d, i$ Robert P. Finger ${ }^{a}$ \\ aDepartment of Ophthalmology, University Hospital Bonn, Bonn, Germany; ${ }^{b}$ Department of Ophthalmology, \\ Queen Elizabeth Hospital Birmingham, University Hospitals Birmingham NHS Foundation Trust, Birmingham, UK; \\ 'Academic Unit of Ophthalmology, Institute of Inflammation \& Ageing, College of Medical and Dental Sciences, \\ University of Birmingham, Birmingham, UK; ${ }^{d}$ Health Data Research UK, London, UK; ${ }^{e}$ Berlin Institute of Health, \\ Charité-Universitätsmedizin Berlin, corporate member of Freie Universität Berlin, Humboldt-Universität zu Berlin, \\ Berlin, Germany; fDivision of Optometry and Visual Sciences, School of Health Sciences, City, University of London,

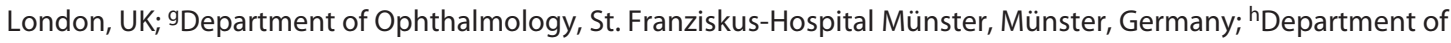 \\ Ophthalmology, University Duisburg-Essen, Essen, Germany; 'NIHR Biomedical Research Centre at Moorfields Eye \\ Hospital NHS Foundation Trust and UCL Institute of Ophthalmology, London, UK
}

\section{Keywords}

Endpoint - Outcome - Outcome measure - Biomarker · Imaging biomarker · Instrument-based measure - Uveitis · Inflammatory eye diseases

\begin{abstract}
Most uveitis entities are rare diseases but, taken together, are responsible for $5-10 \%$ of worldwide visual impairment which largely affects persons of working age. As with many rare diseases, there is a lack of high-level evidence regarding its clinical management, partly due to a dearth of reliable and objective quantitative endpoints for clinical trials. This review provides an overview of available structural outcome measures for uveitis disease activity and damage in an anatomical order from the anterior to the posterior segment of the eye. While there is a multitude of available structural outcome measures, not all might qualify as endpoints for clinical uveitis trials, and thorough testing of applicability is warranted. Furthermore, a consensus on endpoint definition, stan-
\end{abstract}

dardization, and "core outcomes" is required. As stipulated by regulatory agencies, endpoints should be precisely defined, clinically important, internally consistent, reliable, responsive to treatment, and relevant for the respective subtype of uveitis. Out of all modalities used for assessment of the reviewed structural outcome measures, optical coherence tomography, color fundus photography, fundus autofluorescence, and fluorescein/indocyanine green angiography represent current "core modalities" for reliable and objective quantification of uveitis outcome measures, based on their practical availability and the evidence provided so far.

(C) 2021 S. Karger AG, Basel

\section{Introduction}

Most uveitis entities are rare diseases but, taken together, are responsible for 5-10\% of worldwide visual impairment which largely affects individuals of working age [1-4]. As with many rare diseases, there is a dearth of karger@karger.com

(c) 2021 S. Karger AG, Basel

www.karger.com/oph
Correspondence to:

Robert P. Finger, robert.finger@ukbonn.de

Karger" 
evidence regarding its clinical management $[3,4]$. Prerequisites for high-level evidence around disease outcome and therapeutic efficacy are reliable and objective quantitative endpoints, which are necessary, for example, in randomized controlled clinical trials. Currently, we largely lack such endpoints for uveitis, as disease activity is primarily evaluated on clinical examination using subjective gradings with poor reliability [4-7]. This negatively impacts the implementation of randomized controlled clinical trials and generation of high-level evidence.

Historically, only clinical evaluation was available for uveitis assessment and intraocular inflammation ratings $[8,9]$, and it has been the reference standard for many years. The Standardization of Uveitis Nomenclature (SUN) initiative undertook a critical rationalization of a number of key metrics. However, in general terms, clinical examination assessments have the limitations of being subjective, frequently have relatively poor agreement between different clinicians, and are relatively imprecise (being qualitative or semiquantitative ratings) [4-7].

In contrast, instrument-based outcome measures offer objective measures which are potentially more reliable and more precise, being quantifiable alternatives for the assessment of various ocular endpoints including intraocular inflammation and thus uveitis activity. Ophthalmic imaging emerged in the late 1920s with the first available color fundus photography devices [10], and capabilities expanded with the development of fluorescein angiography in the 1960s [11] and indocyanine green angiography in the 1970s [12]. With the advent of technological advancement over the last few decades, many additional imaging modalities have been developed and implemented in routine clinical practice, which allows for a multimodal approach to disease evaluation and a variety of available structural outcome measures.

However, these numerous available different endpoints considerably increase heterogeneity in outcomes, which limits comparability of trials and hampers development of clinical practice guidelines [4]. To further facilitate a consensus on endpoints used for uveitis, an overview on available structural outcome measures is warranted.

When employing outcome measures, it is helpful to clearly stratify for measures of current disease activity (hence of a reversible nature) and of disease complications or permanent structural changes representing damage (of an irreversible nature). Against this background, we will review available structural outcome measures for uveitis disease activity and damage in an anatomical order from the anterior to the posterior segment of the eye, including those with proven or potential use as outcome measures.

\section{Methods}

MEDLINE was searched using truncations and abbreviations of the following terms with no time restrictions: uveitis, Birdshot, choroiditis, Koyanagi, placoid pigment, acute retinal necrosis, progressive outer retinal necrosis, punctate inner, pigment epitheliopathy, white dot, vitritis, acute zonal occult, retinitis, vasculitis, sarcoidosis, Behçet, behcet, inflammatory eye disease, endpoint, outcome, measure, biomarker, quantitative, instrument, automated, algorithm, and computer. Only literature with English abstracts was included. No meta-analysis on outcome measure validity and reliability was performed, as this was beyond the scope of this narrative review. Any sequel of scleritis or of secondary glaucoma due to uveitis in terms of measures of disease damage (e.g., retinal nerve/ganglion cell layer damage) were excluded.

\section{Anterior Segment}

Anterior Chamber Cells

One of the most common signs of inflammatory activity in uveitis are anterior chamber cells. Various semiquantitative classification systems for clinical grading have been described, and the most common and established one was introduced by Hogan et al. [8], encompassing " $1+$ " to " $4+$," and later adapted by the SUN Workshop of 2005 to add an additional "0.5+" class [13]. Optical coherence tomography (OCT, Fig. 1) and laser flare-cell photometry have been proposed for objective grading of anterior chamber cells. While both offer an objective and potentially automated quantification and have a high correlation with the clinical grading, OCT is likely to become the dominant technique for anterior chamber cell quantification, as it is well established and offers a higher data volume [14-16]. Recently, it has been suggested to differentiate the anterior chamber cell population using spectroscopic OCT, which could allow stratification of different leucocyte cell populations [17].

\section{Anterior Chamber Flare}

Anterior chamber flare grading for assessment of disease activity is variable in use, as it is influenced by many factors, for example, lens status and drug-induced mydriasis, yet it constitutes an essential part of clinical evaluation $[8,18]$. Similar to anterior chamber cell grading, the currently established clinical anterior chamber flare grading was already introduced in the 1950s by Hogan and colleagues [8] and classifies flare from " $1+$ " to " $4+$ " based on visibility of iris details on slit-lamp examination. A variety of instruments has been proposed for objective anterior chamber flare assessment, with noninvasive laser flare photometry being the most validated technique, showing a moderate to strong correlation with the clinical SUN classification grading, as well as the anterior chamber protein concentration [19]. Additional methods proposed include OCT, ocular flare analysis meter, and doublepass technique (providing combined information on aberration and intraocular scatter) $[15,19-21]$.

\section{Keratic Precipitates}

Keratic precipitates are another measure of disease activity and can be clinically stratified into granulomatous ("mutton fat") and nongranulomatous (and stellate, fine, and pigmented, i.e., old) [8]. Using in vivo confocal microscopy, keratic precipitates can be further stratified, for example, globular, infiltrating, smooth-round- 
Fig. 1. Anterior chamber cells and flare on swept-source optical coherence tomography in a case of anterior uveitis (ANTERION; Heidelberg Engineering; for better visualization, contrast has been decreased and brightness increased via postprocessing).

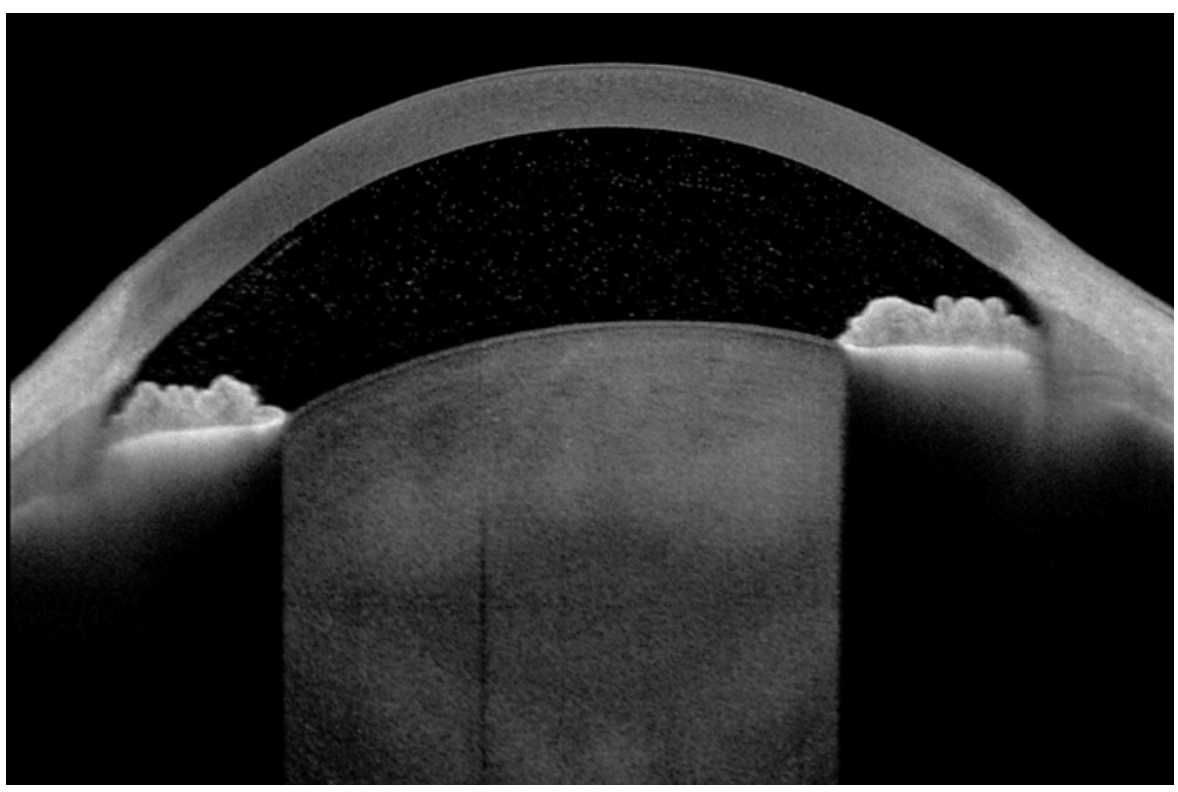

ed, stippled, dendritiform, and cruciform, which may aid in differentiating infectious from noninfectious anterior uveitis [15, 22-34]. Keratic precipitates can also be visualized on OCT; however, further research is necessary to determine its clinical relevance [35].

Other Anterior Segment Outcome Measures

Besides anterior chamber cells, flare, and keratic precipitates, endothelial dust, iris nodules, and conjunctival injection are additional possible measures for disease activity which can be graded clinically or on slit-lamp photographs [15]. Conjunctival congestion is classified dependent on extent [8]. There can be additional corneal involvements which are measures of disease activity including corneal dendrites in cases of secondary uveitis in herpes simplex keratitis and interstitial keratitis, for example, in syphilis. Furthermore, there can be secondary findings of disease activity like corneal opacity and Descemet membrane folds in case of increased intraocular pressure. An additional potential measure of disease activity in the anterior segment of the eye are alterations of iris and episcleral perfusion, which can be analyzed by fluorescein, indocyanine green, and indirectly by OCT angiography (OCT-A) [15, 36-38].

Measures of disease damage in anterior uveitis include anterior/posterior synechiae, iris atrophy, iris depigmentation, secondary cataract, and corneal endothelial cell density. Corneal endothelial cell density is reduced in certain anterior uveitis entities including chronic severe inflammation with granulomatous keratic precipitates, Fuchs uveitis, and viral anterior uveitis and can be assessed by corneal endothelial specular microscopy $[15,39]$. However, dependent on the available optical resolution, this can be challenging. Anterior segment structural changes like synechiae and iris atrophy can also be assessed on OCT or slit-lamp photography, which can facilitate objective and reliable quantification as well as comparison over time $[15,40]$.

Structural Endpoints in Uveitis

\section{Vitreous}

Vitreous Cells

Vitreous cells, a sign of inflammatory activity, which are thought to be predominantly T lymphocytes in uveitis [41], are clinically assessed as they have been described by Kimura et al. [9], which was later extended to a semiquantitative scale from " $1+$ " to "4+" [42]. Slit-lamp examination and funduscopy allow assessment of anterior and posterior vitreous cells. However, both anterior and posterior vitreous body cell assessment do not take into account the total spatial distribution of inflammatory cells in the vitreous. Although it was agreed that the presence of vitreous cells was an important clinical feature, no consensus could be reached on a standard grading system.

Additionally to floating vitreous body cells seen on clinical examination, hyperreflective preretinal deposits and deposits/consolidations at the posterior surface of the vitreous can be present on OCT in specific uveitis entities (including toxoplasmosis, syphilis, and candida chorioretinitis) [40,43]. In case of massive deposits, a shadowing effect is generated which is sometimes described as "rain-cloud sign" $[40,43]$.

\section{Vitreous Haze and Opacities}

Vitreous inflammation can be evaluated in a more general and potentially more accurate $[42,44]$ manner by assessment of vitreous haze and opacities. Initially, evaluation was based on a qualitative 5-step grading of the haze and classification of opacities as fine/coarse/stringy [9]. To try to improve objectivity, Nussenblatt et al. [44] proposed a 6-step scale in which the examiner compared the indirect biomicroscopic view of the fundus against reference images; this was later adapted by the SUN initiative [13], replacing the trace grade with a 0.5 . To further improve discrimination and objectivity, Davis and colleagues [45] expanded this to a 9-step scale in which fundus photographs are taken under standard conditions, and these photographs are compared to a reference set of images. Reliability of both pro- 
posed scales for clinical vitreous haze grading was moderate with the 9 -step scale potentially being more suitable for clinical trials $[5,6,46]$. It is important to bear in mind that correction of vitreous haze grading for any other media opacities, for example, lental or corneal, is essential and that this is a further subjective element that may reduce reliability.

To allow truly objective quantification of vitreous haze, OCT has been proposed for quantification of vitreous haze, and first applications are promising with good reliability and correlation with the clinical grading [47-49]. Furthermore, there are promising first attempts for automated vitreous haze grading on color fundus photography [50]. Further, ultrasound biomicroscopy and vitreous fluorophotometry can provide additional information over clinical examination on vitritis/pars planitis activity $[15,51,52]$.

In addition to vitreous cells and haze, inflammatory activity can be assessed by presence of snowballs and/or snowbanks (especially if newly appearing) [9]. Possible disease complications of vitreous inflammation include vitreous detachment and/or retinal breaks [9]. Importantly, all discussed measures only provide a grading of inflammation in a relatively small part of the total vitreous body.

\section{Epiretinal Membrane}

One additional possible complication from retinal/vitreous inflammation is the formation of a secondary epiretinal membrane, which can contribute independently to vision loss in uveitic eyes. It can be assessed by funduscopic examination, blue reflectance imaging, multicolor imaging, and OCT, though the latter is thought to be the most sensitive for its identification $[53,54]$.

\section{Retina and Choroid}

\section{Macular Intra-/Subretinal Fluid}

Intra- and subretinal fluid is a common sign of inflammation in uveitis (especially in presence of chronic disease [55]) and can have a profound impact on central visual acuity and patient-reported outcome measures such as quality of life $[55,56]$. Its diagnosis and evaluation was revolutionized by the advent of OCT, which allows for a reliable assessment and quantification of central retinal changes $[57,58]$. Macular fluid can present in uveitis as diffuse and cystoid intraretinal or subretinal fluid, and these subentities may respond differently on treatment [55, 59-61]. Its application as an objective, quantitative endpoint for uveitis is well established and could be used as a blueprint for the development of novel quantitative endpoints [4,62-80]. A 20\% change in retinal thickness in patients with macular edema seems to be optimal for clinically important changes in visual acuity and may therefore be considered as an endpoint for clinical trials [68]. Disorganization of retinal inner layers is a surrogate marker of visual acuity in participants with current or resolved uveitic macular edema [81]. Uveitic macular edema may show morphological characteristics discriminating it from other causes of macular edema $[82,83]$.

Yet, while OCT has widely become the reference standard for evaluation of macular edema, fluorescein angiography still has additional diagnostic value, as both imaging techniques are complementary investigations revealing potentially different pathophysiologic aspects of macular edema. Fluorescein angiography is more sensitive in detecting very subtle macular leakage which may represent mild edema or leakage in the absence of edema [58, 8489].
Retinal and Chorioretinal Inflammatory Lesions

Appearance of retinal/choroidal lesions on funduscopic examination and color fundus photography in terms of color, border "fluffiness"/"fuzziness," hemorrhage, prominence, opacity of the lesion, and surrounding retinal edema is a well-known measure of disease activity [9]. Dependent on the specific disease entity, evaluation on various other imaging techniques can provide valuable additional information.

The substructure of retinal/choroidal lesions can be assessed by OCT and frequently reveals hyperreflective aspects [40, 43, 90]. Furthermore, dependent on disease entity and activity, specific retinal layers can be disrupted/thickened/altered in characteristic ways $[43,91,92]$. For example, disruption of the ellipsoid zone in multiple evanescent white dot syndrome (MEWDS) is thought to correspond to swollen photoreceptor bodies [43]. Several diseases are associated with subretinal material, which can be a sign of active inflammation: for example, in Vogt-Koyanagi-Harada disease, sympathetic ophthalmia, vitreoretinal lymphoma (as masquerade syndrome), and subretinal fibrosis [43]. Choriocapillaris hyporeflectivity can be present in primary inflammatory entities of the choriocapillaris and might represent a disease complication [43]. In addition, near-infrared reflectance can be useful in some posterior uveitis entities including white dot syndromes and might indicate impairment of the photoreceptor layer (Fig. 2) [90, 93].

Fundus autofluorescence has emerged as a noninvasive imaging technique that uses the fluorescent properties of intrinsic fluorophores to evaluate the retinal pigment epithelium/photoreceptor complex [94]. Fundus autofluorescence characteristics of retinal/choroidal lesions can be described in terms of hypo-/iso-/ hyperautofluorescence and can be used to evaluate inflammatory activity and size and number of inflammatory retinal/choroidal lesions in uveitis (Fig. 2). As appearance of lesions on fundus autofluorescence is likely of prognostic value, it has been suggested for monitoring of retinal/choroidal lesions and can also aid automatic quantification of retinal/choroidal lesions [95-99]. Different fundus autofluorescence modalities might differ in eligibility dependent on excitation wavelengths and concomitant different penetration depths and molecular targets for excitation. Moreover, quantitative autofluorescence may provide additional insights and objective measures [100].

Additional imaging modalities which can provide insightful information for evaluation of retinal/choroidal lesions are fluorescein and indocyanine green angiography. Differentiation of angiographic findings as staining, leakage, blocking, or true capillary dropout can be helpful in stratification of different uveitis entities as well as assessment of intraocular inflammation, but may also pose challenges due to, for example, similarities in angiographic appearances. Fluorescein leakage in the area of retinal/choroidal lesions can indicate disease activity. Dependent on disease entity, hypo-/hyperfluorescence due to staining/pooling/window defects/blocking by retinal/choroidal lesions or in areas of clinically uninvolved fundus during different stages of angiography (early vs. late) and disease can be present [101-103]. Certain retinal pigment epithelium alterations can be visualized by characteristic fluorescein angiography patterns (e.g., "retinal pigment epithelium mottling" in acute posterior multifocal placoid pigment epitheliopathy and serpiginous choroiditis) [101].

Wide-field retinal imaging is a very relevant addition to the current imaging modalities as it allows for the additional visualization of peripheral lesions/ischemia/vasculitis and therefore can alter 
Fig. 2. Chorioretinal lesions in punctuate inner choroidopathy on "blue" fundus autofluorescence (450-nm excitation wavelength, left) and near-infrared reflectance imaging (right; both Spectralis HRA; Heidelberg Engineering).
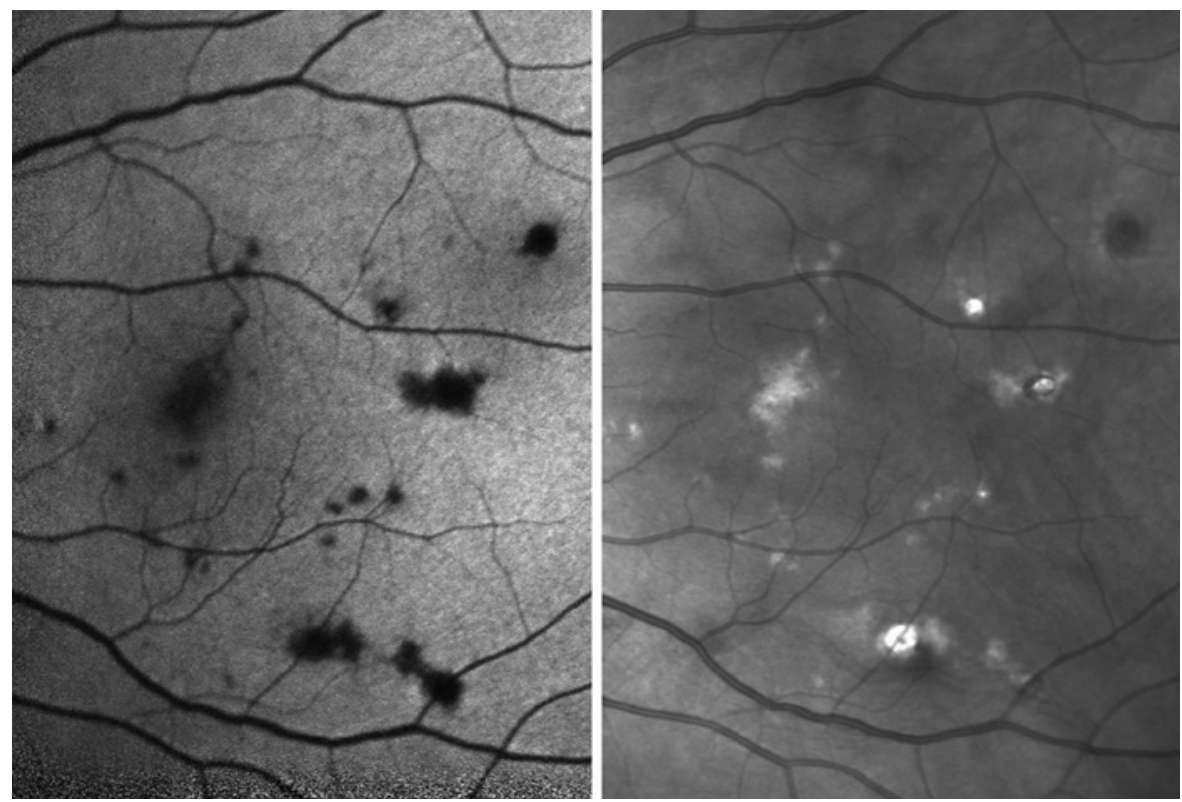
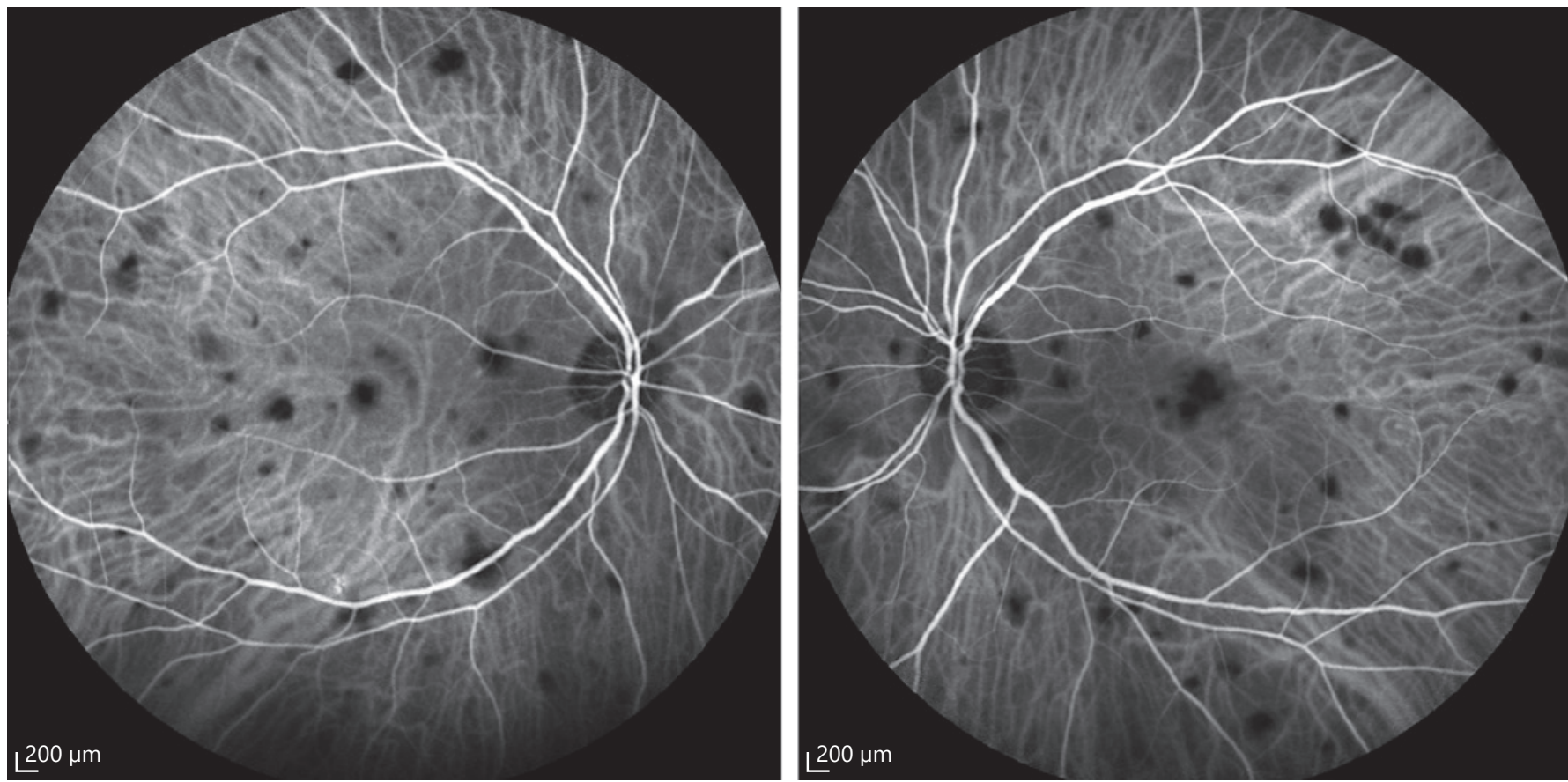

Fig. 3. Bilateral choroidal granulomas on indocyanine green angiography visible as hypofluorescent "dark dots" in a case of birdshot retinochoroidopathy (intermediate phase; Spectralis HRA; Heidelberg Engineering).

management decisions compared to standard-of-care imaging and clinical examination in posterior and intermediate uveitis [104108]. Adaptive optics imaging might allow identification of additional imaging biomarkers such as irregularities in the reflectivity of the photoreceptor mosaic and stratification of vascular sheathing (see also "vasculitis" below), which could serve as endpoints in uveitis trials [109-113]. Although chorioretinal lesions can simply be a sign of acute disease activity with complete resolution, they are commonly associated with scarring and other complications such as ischemia and neovascular or epiretinal membrane formation.

Choroidal Granulomas and Choroidal Thickening/Thinning

Stromal choroidal inflammatory activity in terms of choroidal granulomas as in birdshot retinochoroidopathy, Vogt-Koyanagi- 

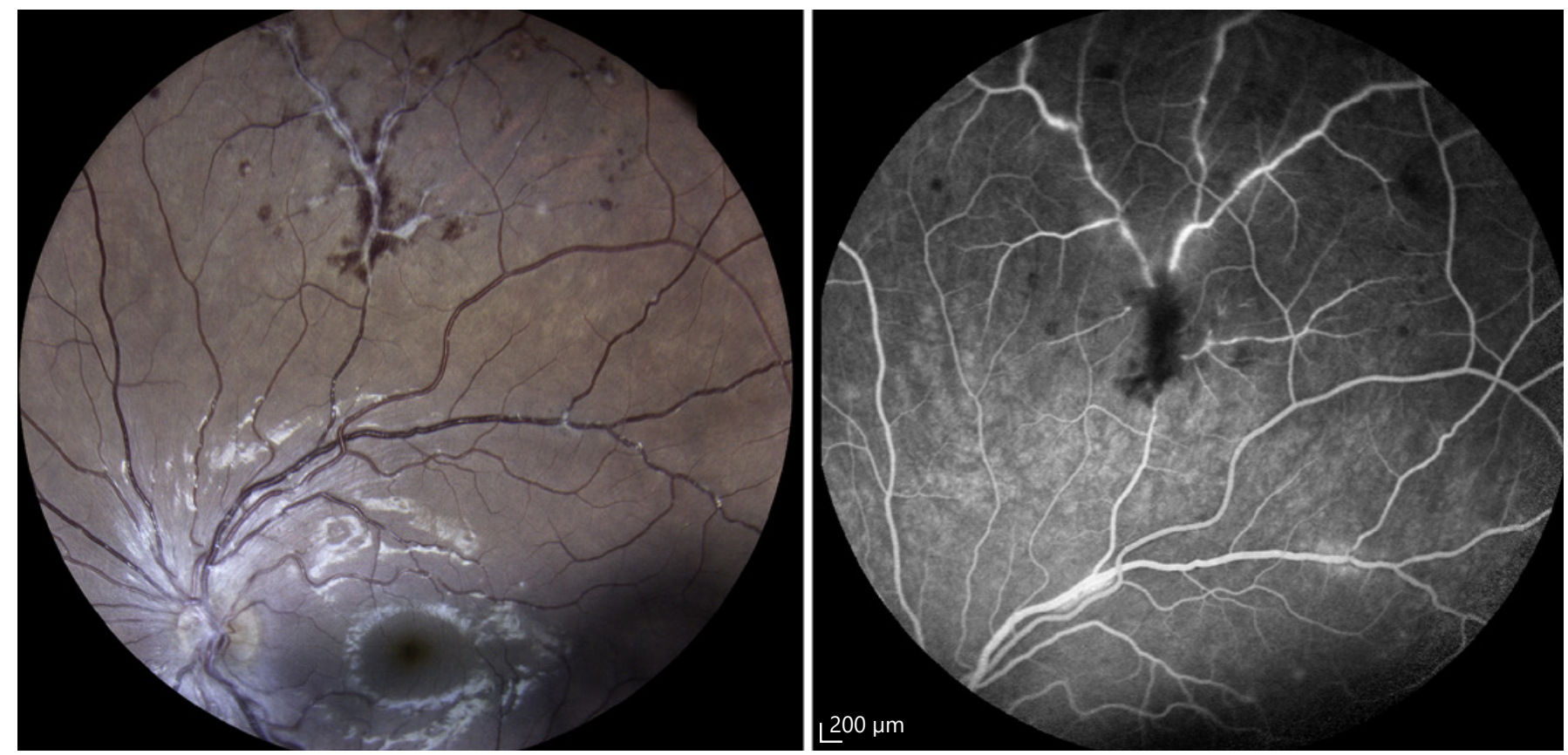

Fig. 4. Vasculitis signs on color fundus photography (left; Eidon; CenterVue) and fluorescein angiography in a case of idiopathic retinal vasculitis (right; late phase; Spectralis HRA; Heidelberg Engineering).

Harada disease, sympathetic ophthalmia, sarcoidosis, and tuberculosis can be assessed using indocyanine green angiography, and a standardized angiographic protocol to increase reliability has been proposed (Fig. 3) [114, 115]. These choroidal granulomas can potentially also be visualized noninvasively on OCT and OCT-A; however, the limited depth resolution should be taken into account [40, 43, 116-118]. Enhanced depth imaging OCT may help to differentiate between etiologies and also to monitor therapy, as it allows improved visualization of choroidal structures $[119,120]$.

Due to choroidal infiltration by inflammatory cells or granulomas or increased filling of the choroidal vasculature, choroidal thickening can occur, either globally or associated with localized retinal/choroidal lesions [43]. Choroidal thickness varies during different stages of disease, and it can indicate disease activity, for example, Vogt-Koyanagi-Harada disease, acute zonal occult outer retinopathy, and birdshot retinochoroidopathy [121-124]. It can be assessed on enhanced depth spectral-domain and swept-source OCT, with the latter being superior because of a higher signal penetration depth $[117,125]$. Besides variations in thickness, choroidal involvement can also be present in terms of small structural and reflectivity changes visible on enhanced depth spectral-domain and swept-source OCT (e.g., hyperreflective dots and diffuse hypo-/hyperreflectivity) [126]. Furthermore, the ratio of luminal and stromal interstitial choroidal area (choroidal vascularity index) can be quantified on OCT and may aid monitoring disease activity [127].

\section{Choriocapillary Nonperfusion}

Choriocapillary nonperfusion due to presumed inflammatory lesions (unspecific measure of disease activity)/atrophy (measure of disease damage) in the early phase of fluorescein angiography and in the intermediate and late phase of indocyanine green angiography is typically seen in primary inflammatory entities of the choriocapillaris (e.g., acute posterior multifocal placoid pigment epitheliopathy, MEWDS, and serpiginous choroiditis) [87] and can also be assessed noninvasively using OCT-A (however, masking and projection artifacts need to be taken into account as possible confounders) $[38,40,128]$. These nonperfused areas of choriocapillaris can be associated with funduscopically visible retinal/ choroidal lesions, but can also occur in areas without any funduscopical sign of chorioretinal involvement.

Furthermore, choriocapillaris flow voids on OCT-A can also occur in other uveitis entities, which have been described for different pathologies and may serve as markers of disease activity or complications [129-131]. As OCT-A has a minimum blood flow velocity threshold for detection of perfusion, no detected signal on OCT-A needs to be primarily defined as a subthreshold signal. Hence, it does not allow for a differentiation of very slow perfusion, which is not picked up by OCT-A, from no perfusion.

\section{Vasculitis/Capillary Leakage}

Retinal vasculitis can be an important sign of activity in various posterior uveitis entities including Behçet's disease, sarcoidosis, tuberculosis, and birdshot retinochoroidopathy. Presence and severity of retinal vasculitis can be assessed clinically by funduscopic examination as well as by color fundus photography (Fig. 4, perivascular sheathing, hemorrhage, vascular occlusions, and cottonwool spots) and fluorescein angiography (leakage and vascular staining, preferable for assessment of inflammatory activity) $[9,88$, $89,102,109,132-135]$ Vasculitis can be stratified into arterial (arteriolitis) and venous (phlebitis) involvement, and capillary leak- 


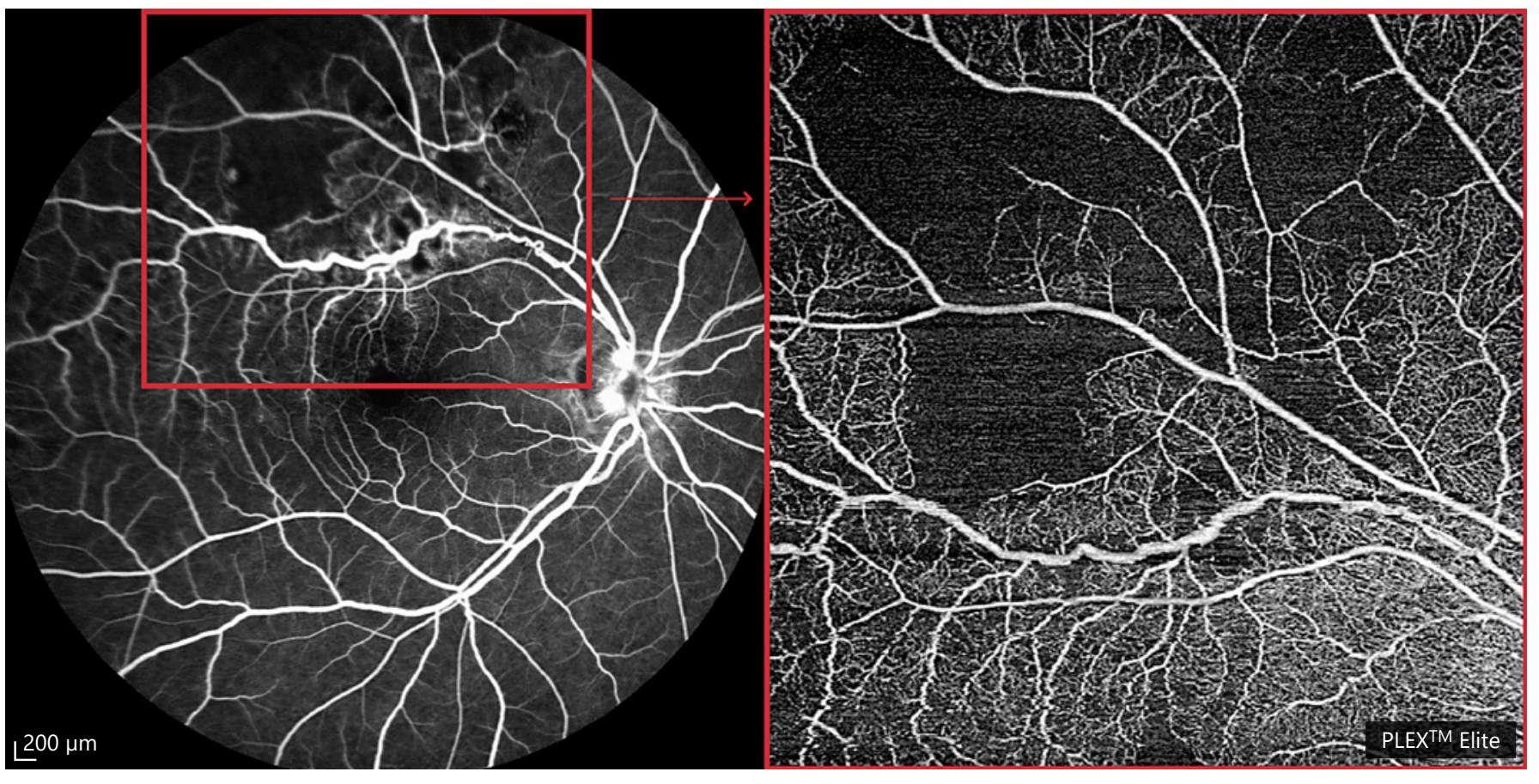

Fig. 5. Assessment of retinal capillary dropout on fluorescein (left; late phase; Spectralis HRA; Heidelberg Engineering) and optical coherence tomography angiography in a case of idiopathic occlusive retinal vasculitis (right; PLEX Elite 9000; Zeiss Meditec).

age can be present diffusely, peripherally, focally, or in certain "patterns" such as the wreath-like hyperfluorescence in MEWDS $[101,103,108,118,136-138]$. Vasculitis can also be present in the choroidal stroma, for example, in Vogt-Koyanagi-Harada disease or in sarcoidosis, where leakage can be assessed by indocyanine green angiography $[114,115]$. Certain characteristic angiographic findings may be indicative of specific uveitis entities, such as pinpoint leakage on fluorescein and indocyanine green angiography in Vogt-Koyanagi-Harada disease.

\section{Retinal Nonperfusion}

Retinal capillary dropout, for example, as a result from occlusive vasculitis, can be examined and quantified on fluorescein angiography and OCT-A (Fig. 5). Automated quantification of retinal nonperfusion on OCT-A is well established [129, 139]. While capillary dropout as a vasculitis sequel is usually a measure of irreversible disease damage, capillary dropout on OCT-A needs to be interpreted with caution. Again, the potential confounding due to subthreshold perfusion needs to be kept in mind when interpreting OCT-A imaging (see above). In addition, retinal atrophy can occur as a common consequence of retinal capillary dropout. While retinal capillary dropout is a common sequel of retinal vasculitis, it can also occur in cases without obvious presence of retinal vasculitis, for example, in intermediate uveitis $[38,129,140]$. In addition, quantification of the microcirculation in the peripapillary area by OCT-A may be a useful indicator for capillary insufficiency and impairment of ocular blood flow as a long-term complication from inflammation [141].
Optic Disc Edema and Inflammation

Optic disc edema is a sign of disease activity and can be assessed and quantified by clinical examination [9], though much more reliably and objectively on fluorescein angiography (as a "hot disc") and OCT $[43,87,117]$. Optic disc hyperfluorescence on indocyanine green angiography is thought to represent an additional measure of disease activity in severe cases [87].

\section{Retinal/Choroidal Neovascularization}

Inflammatory retinal/optic disc/choroidal neovascularizations can be complications of various posterior uveitis/panuveitis entities including sarcoidosis, Behçet's disease, punctate inner choroidopathy, multifocal choroiditis, serpiginous choroiditis, and tuberculosis-associated choroiditis and could hence serve as endpoints for disease progression/complication [142-145]. Although the secondary neovascularizations can be detected by fluorescein or OCT angiography, fluorescein angiography remains the reference standard for determining neovascular activity [142, 146150]. Discrimination of neovascular activity and inflammation from a retinal lesion can be challenging, and OCT and OCT-A can aid differentiation $[144,151,152]$. Moreover, OCT-A can outperform fluorescein angiography in detection of choroidal neovascularizations in certain cases and may offer a valuable instrument for neovascularization follow-up, which could aid monitor treatment $[145,150,152-155]$. 


\section{Conclusion}

To date, numerous different structural outcome measures have been used to assess uveitis inflammatory activity and disease damage, and this considerable heterogeneity in outcomes limits comparability of studies currently available. Stratification for disease activity and disease damage outcomes is essential, as the former is potentially more relevant for therapeutic management. A new consensus for how disease activity in uveitis should be measured and a consensus on "core outcomes" is warranted. High-priority areas include childhood uveitis and uveitis involving the posterior segment $[4,156-160]$. This might not only increase comparability of uveitis trials, but also may facilitate development of guidelines for clinical practice and drug approval and in the end would improve uveitis patient care [4]. In addition, the field would benefit from clear definitions for standardized endpoint assessment, including the unit/scale used for the respective endpoint (e.g., cells $/ \mathrm{mm}^{3}$ for anterior chamber cell quantification) and a clear definition of the anatomic location in which the analysis is performed and of the algorithms used for analyses (as results can vary dependent on the device manufacturer) $[16,161]$.

Given the enormous amount of available different structural outcome measures employed across different uveitis entities, clear criteria for their evaluation are needed. Important requirements for any endpoint stipulated by regulators and in the available literature are a precise definition, clinical importance, internal consistency in terms of plausibility and validity (is there a true association with visual function and control of disease?), reliability, responsiveness to treatment, and relevance for the respective subtype of uveitis [162-165]. To date, none of the reviewed studies has demonstrated all of this for any of the described outcome measures which highlights that further work is required in this area.

The established endpoints for clinical trials in uveitis are new inflammatory lesions, vitreous haze, anterior chamber cells, and best-corrected visual acuity $[165,166]$. However, while visual acuity may be one of the most obvious and natural endpoints for ophthalmic diseases in general, it has been shown to be too insensitive and not relevant for many uveitis cases and is no longer regarded as an appropriate sole primary efficacy endpoint in uveitis [165]. Yet, it is still used by a majority of clinical uveitis trials. All of the clinical ratings lack reproducibility which is problematic for any clinical trial endpoint [18, $156,157,167]$. This dilemma is reflected in a statement by the European Medicines Agency highlighting the great need for novel endpoints including aspects of structural changes especially in intermediate and posterior uveitis [165].

A general agreement on endpoints is complicated by the extent of possible structural changes on multimodal imaging and the variety of disease-specific findings. Against this background, disease-specific activity scales and endpoints may be appropriate at least in some instances [18]. Endpoints can serve multiple purposes which should be considered when developing or choosing outcome measures including diagnostic, monitoring, and prognostic applications [161].

As highlighted, many of the current shortcomings of outcome measures are determined by the nature of the clinical assessment they are based on. The instrumentbased automated methods for endpoint quantification reviewed herein may overcome many of these shortcomings, for example, are better reproducible and also more time and cost efficient compared to manual grading, especially for large studies or datasets [168]. Any development of automated quantification of, for example, intraocular inflammation, would benefit from precise definitions of imaging biomarkers present in uveitis as reviewed here.

In addition to structural outcome measures reviewed herein, functional, patient-reported (e.g., vision-related quality of life), and outcome measures for cost-effectivity analyses are additional important outcome measures also applicable to uveitis trials. In addition, anterior chamber-/vitreous-/serum-based laboratory measures could additionally prove useful as novel outcome measures [169-172]. For example, first studies suggest a possible application of aqueous microRNA analyses in uveitis trials $[169,170]$. However, these are still rather experimental and have not been widely implemented in uveitis clinical research.

A commonly used concept is the composite endpoints; however, while composite endpoints can simplify interpretation of clinical trial results, their use remains problematic, as they are often unreasonably combined, inconsistently defined, and inadequately reported [173]. These issues can confound perception of significance of trial results. Therefore, positive composite primary outcomes must be carefully analyzed to determine which components are driving the result [174].

In conclusion, while our review illustrates the multitude of available structural outcome measures, not all might qualify as endpoints for clinical uveitis trials, and thorough testing of applicability is warranted. Although there is a great need for novel, quantifiable structural out- 
Table 1. Overview on imaging modalities and their possible use in assessment of uveitis activity and complications

\begin{tabular}{lll}
\hline Modality & Assessment of uveitis activity & Assessment of uveitis complications \\
\hline Optical coherence tomography & $\begin{array}{l}\text { Anterior chamber cells [14-16] and flare [19, 175], keratic } \\
\text { precipitates [35], vitreous haze [47-49], hyperreflective preretinal/ } \\
\text { vitreous deposits [40, 43], intra- and subretinal fluid [4, 57, 59, 62-79, } \\
\text { 82, 83, 88, 89, 176], structure of retinal/choroidal lesions [40, 43, } \\
\text { 90-92] [43, 117], choroidal thickness and reflectivity [40, 43, 117, 119, } \\
\text { 121-127], optic disc edema [43,117] }\end{array}$ & $\begin{array}{l}\text { Epiretinal membrane [54], presence of retinal/ } \\
\text { chions [40, 43, 90], cataract [177, 178] }\end{array}$ \\
\hline
\end{tabular}

Laser flare-cell photometry Anterior chamber cells [14-16] and flare [14, 15, 19, 21, 117, 179-

185]

Corneal endothelial specular

Endothelial cell loss [15, 39, 186-188]

microscopy

\begin{tabular}{|c|c|c|}
\hline In vivo confocal microscopy & Keratic precipitates $[15,23-34,118,120]$ & \\
\hline Slit-lamp photography & $\begin{array}{l}\text { Keratic precipitates, endothelial dust, anterior chamber cells and } \\
\text { flare, hypopyon, iris nodules, conjunctival injection }[15,24,189-192]\end{array}$ & $\begin{array}{l}\text { Corneal opacifications, synechiae, iris atrophy, } \\
\text { heterochromia, iris depigmentation, cataract } \\
{[15,189-191]}\end{array}$ \\
\hline Fluorescein angiography & $\begin{array}{l}\text { Episcleral and scleral perfusion }[15,36,37] \text {, macular edema }[85-89, \\
193,194] \text {, vasculitis/leakage of retinal vessels }[89,101-103,108,109 \text {, } \\
118,132-138] \text {, optic disc edema }[87]\end{array}$ & $\begin{array}{l}\text { Retinal and choriocapillary nonperfusion }[87] \\
\text { retinal/choroidal neovascularization }[142,145- \\
150,152-155]\end{array}$ \\
\hline $\begin{array}{l}\text { Optical coherence tomography } \\
\text { angiography }\end{array}$ & $\begin{array}{l}\text { Iris vessel dilation [38], choroidal flow voids due to choroidal } \\
\text { granulomas }[43,116-118] \text {, choriocapillary nonperfusion }[38,40 \text {, } \\
128-131]\end{array}$ & $\begin{array}{l}\text { Retinal and choriocapillary nonperfusion }[38 \text {, } \\
129,140,141] \text {, retinal and choroidal } \\
\text { neovascularizations }[38,144,145,148-155]\end{array}$ \\
\hline Color fundus photography & $\begin{array}{l}\text { Vitreous haze [50], appearance of retinal/choroidal lesions }[9,135 \text {, } \\
192,195]\end{array}$ & $\begin{array}{l}\text { Epiretinal membrane [54], presence and size of } \\
\text { retinal/choroidal lesions }[9,135,192,195]\end{array}$ \\
\hline
\end{tabular}

Fundus autofluorescence Appearance of retinal lesions [95-100, 117]

Presence and size of retinal lesions [95-100, 117]

Structural endpoints requiring further evidence are shown in nonbold font. Spectroscopic OCT [17], ocular flare analysis meter [19, 199], double-pass technique [19, 20, 200], vitreous fluorophotometry [51], multicolor imaging [53], and adaptive optics imaging [109-113] are additional imaging modalities requiring more evidence.

come measures, a consensus on endpoint definition, standardization, and "core outcomes" is required first. Available endpoints reviewed herein and their corresponding modalities are summarized in Table 1, and endpoints requiring further evidence are indicated. Out of all modalities used for assessment of the reviewed structural outcome measures, OCT, color fundus photography, fluorescein/indocyanine green angiography, and fundus autofluorescence may represent "core modalities" for reliable and objective quantification of uveitis outcome measures, based on their practical availability and the evidence provided so far.

Structural Endpoints in Uveitis

\section{Conflict of Interest Statement}

Maximilian W. M. Wintergerst: DigiSight Technologies: travel grant; D-EYE Srl: imaging devices; Heine Optotechnik GmbH: research funding, imaging devices, travel reimbursements, and consultant; Eyenuk, Inc.: free trial analysis; ASKIN \& CO GmbH: travel reimbursement and honoraria; Berlin-Chemie AG: grant and travel reimbursements; imaging devices were provided by Heidelberg Engineering, Optos, Carl Zeiss Meditec, and CenterVue. Xiaoxuan Liu: funding was provided by the Wellcome Trust, through a Health Improvement Challenge grant (200141/Z/15/Z); no conflicts of interest. Jan H. Terheyden: imaging devices were provided by Heidelberg Engineering, Optos, Carl Zeiss Meditec, and CenterVue. Dominika Pohlmann: participant in the BIH Charité Cli- 
nician Scientist Program funded by the Charité-Universitätsmedizin Berlin and the Berlin Institute of Health. Grants: Allergan and Bayer. Jeany Q. Li: funding was provided by the FEMHABIL Program, Faculty of Medicine, University of Bonn; no conflicts of interest. Giovanni Montesano: no conflicts of interest. Giovanni Ometto: no conflicts of interest. Frank G. Holz: financial support: Heidelberg Engineering, Optos, Carl Zeiss Meditec, CenterVue, Acucela, Allergan, Bayer, Bioeq, Genentech/Roche, Merz, NightstarX, and Novartis; consultant: Acucela, Bayer, Bioeg, Boehringer-Ingelheim, Genentech/Roche, Heidelberg Engineering, Novartis, and Thea: recipient: Allergan, Bayer, Carl Zeiss MediTec, Genentech/Roche, Heidelberg Engineering, and Novartis; David P. Crabb: speaker fees: Allergan and Santen; research grants: Allergan, Santen, and Apellis; consultant: CenterVue, Santen, and Apellis; Uwe Pleyer: speaker fees: AbbVie, Alcon, Alimera, Allergan, Dompé, Novartis, Pfizer, Santen, Shire, and Thea Winzer; consultant: AbbVie, Allergan, Lilly Novartis, Santen, and Thea; Carsten Heinz: consultant for Alimera Sciences and honoraria from AbbVie and Novartis. Alastair K. Denniston: funding was provided by the Wellcome Trust, through a Health Improvement Challenge grant (200141/Z/15/Z); no conflicts of interest. Robert P. Finger: financial support: Heidelberg Engineering, Optos, Carl Zeiss Meditec, and CenterVue; consultant: Bayer, Novartis, Opthea, Novelion, Santhera, Inositec, Alimera, Ellex, Roche, and RetinaImplant.

\section{Funding Sources}

Funding was provided by the BONFOR GEROK Program, Faculty of Medicine, University of Bonn (Grant No. O-137.0028) to M.W.M.W. and by the Else Kroener-Fresenius Foundation and the German Scholars Organization (EKFS/GSO 16) to R.P.F. Funders had no role in conceptualizing of the project or writing of the manuscript.

\section{Author Contributions}

M.W.M.W., R.P.F., U.P., C.H., and A.K.D. conceptualized the project. M.W.M.W. and R.P.F. did the literature review and drafted the first version of the manuscript. All authors critically reviewed the manuscript, gave final approval, and agreed to be accountable for all aspects of the work in ensuring that questions related to the accuracy or integrity of any part of the work are appropriately investigated and resolved.

\section{References}

1 Suttorp-Schulten MS, Rothova A. The possible impact of uveitis in blindness: a literature survey. Br J Ophthalmol. 1996;80:844-8.

2 Miserocchi E, Fogliato G, Modorati G, Bandello F. Review on the worldwide epidemiology of uveitis. Eur J Ophthalmol. 2013;23: 705-17.

3 Tsirouki T, Dastiridou A, Symeonidis C, Tounakaki O, Brazitikou I, Kalogeropoulos C, et al. A focus on the epidemiology of uveitis. Ocul Immunol Inflamm. 2018;26:2-16.

4 Denniston AK, Keane PA, Srivastava SK. Biomarkers and surrogate endpoints in uveitis: the impact of quantitative imaging. Invest Ophthalmol Vis Sci. 2017;58:BIO131-40.

5 Kempen JH, Ganesh SK, Sangwan VS, Rathinam SR. Interobserver agreement in grading activity and site of inflammation in eyes of patients with uveitis. Am J Ophthalmol. 2008; 146:813-8.e1.

6 Hornbeak DM, Payal A, Pistilli M, Biswas J, Ganesh SK, Gupta V, et al. Interobserver agreement in clinical grading of vitreous haze using alternative grading scales. Ophthalmology. 2014;121:1643-8.

7 Agrawal R, Keane PA, Singh J, Saihan Z, Kontos A, Pavesio CE. Comparative analysis of anterior chamber flare grading between clinicians with different levels of experience and semi-automated laser flare photometry. Ocul Immunol Inflamm. 2016;24:184-93.

8 Hogan MJ, Kimura SJ, Thygeson P. Signs and symptoms of uveitis. I. Anterior uveitis. Am J Ophthalmol. 1959;47:155-70.
9 Kimura SJ, Thygeson P, Hogan MJ. Signs and symptoms of uveitis. II. Classification of the posterior manifestations of uveitis. Am J Ophthalmol. 1959;47:171-6.

10 Bedell AJ. The photographic diagnosis of some punctate retinal conditions. Trans Am Ophthalmol Soc. 1928;26:148-55.

11 Novotny HR, Alvis DL. A method of photographing fluorescence in circulating blood in the human retina. Circulation. 1961;24:82-6.

12 Kogure K, David NJ, Yamanouchi U, Choromokos E. Infrared absorption angiography of the fundus circulation. Arch Ophthalmol. 1970;83:209-14.

13 Jabs DA, Nussenblatt RB, Rosenbaum JT; Standardization of Uveitis Nomenclature (SUN) Working Group. Standardization of uveitis nomenclature for reporting clinical data. Results of the first international workshop. Am J Ophthalmol. 2005;140:509-16.

14 Ladas JG, Wheeler NC, Morhun PJ, Rimmer SO, Holland GN. Laser flare-cell photometry: methodology and clinical applications. Surv Ophthalmol. 2005;50:27-47.

15 Siak J, Mahendradas P, Chee SP. Multimodal imaging in anterior uveitis. Ocul Immunol Inflamm. 2017;25:434-46.

16 Liu X, Solebo AL, Faes L, Beese S, Braithwaite $\mathrm{T}$, Round $\mathrm{ME}$, et al. Instrument-based tests for measuring anterior chamber cells in uveitis: a systematic review. Ocul Immunol Inflamm. 2019;28:1-12.
17 Qian R, Huang WF, McNabb RP, Zhou KC, Liu QH, Kuo AN, et al. Ocular anterior chamber blood cell population differentiation using spectroscopic optical coherence tomography. Biomed Opt Express. 2019;10:3281-300.

18 de Smet MD, Taylor SR, Bodaghi B, Miserocchi E, Murray PI, Pleyer U, et al. Understanding uveitis: the impact of research on visual outcomes. Prog Retin Eye Res. 2011;30:45270.

19 Liu X, McNally TW, Beese S, Downie LE, Solebo AL, Faes L, et al. Non-invasive instrument-based tests for quantifying anterior chamber flare in uveitis: a systematic review. Ocul Immunol Inflamm. 2020:1-9.

20 Díaz-Doutón F, Benito A, Pujol J, Arjona M, Güell JL, Artal P. Comparison of the retinal image quality with a Hartmann-Shack wavefront sensor and a double-pass instrument. Invest Ophthalmol Vis Sci. 2006;47:1710-6.

21 Agrawal R, Keane PA, Singh J, Saihan Z, Kontos A, Pavesio CE. Classification of semi-automated flare readings using the Kowa FM 700 laser cell flare meter in patients with uveitis. Acta Ophthalmol. 2016;94:e135-41.

22 Pillai CT, Dua HS, Azuara-Blanco A, Sarhan AR. Evaluation of corneal endothelium and keratic precipitates by specular microscopy in anterior uveitis. Br J Ophthalmol. 2000;84: 1367-71.

23 Wertheim MS, Mathers WD, Planck SJ, Martin TM, Suhler EB, Smith JR, et al. In vivo confocal microscopy of keratic precipitates. Arch Ophthalmol. 2004;122:1773-81. 
24 Mahendradas P, Shetty R, Narayana KM, Shetty BK. In vivo confocal microscopy of keratic precipitates in infectious versus noninfectious uveitis. Ophthalmology. 2010;117: 373-80.

25 Kanavi MR, Soheilian M, Naghshgar N. Confocal scan of keratic precipitates in uveitic eyes of various etiologies. Cornea. 2010;29: 6504.

26 Kanavi MR, Soheilian M. Confocal scan features of keratic precipitates in granulomatous versus nongranulomatous uveitis. J Ophthalmic Vis Res. 2011;6:255-8.

27 Mocan MC, Kadayifcilar S, Irkec M. Keratic precipitate morphology in uveitic syndromes including Behçet's disease as evaluated with in vivo confocal microscopy. Eye. 2009;23: $1221-7$.

28 Kanavi MR, Soheilian M, Yazdani S, Peyman GA. Confocal scan features of keratic precipitates in Fuchs heterochromic iridocyclitis. Cornea. 2010;29:39-42.

29 Mocan MC, Kadayifcilar S, Irkeç M. In vivo confocal microscopic evaluation of keratic precipitates and endothelial morphology in Fuchs' uveitis syndrome. Eye. 2012;26:11925.

30 Labbé A, Dupas B, Offret H, Baudouin C, Labetoulle $\mathrm{M}$. Evaluation of keratic precipitates and corneal endothelium in Fuchs' heterochromic cyclitis by in vivo confocal microscopy. Br J Ophthalmol. 2009;93:673-7.

31 Gonzales JA, Hinterwirth A, Shantha J, Wang $\mathrm{K}$, Zhong L, Cummings SL, et al. Association of ocular inflammation and rubella virus persistence. JAMA Ophthalmol. 2019;137:4358.

32 Lim LL, Xie J, Chua CC, Wong T, Hoang LT, Becker MD, et al. Vivo Laser confocal microscopy using the HRT-rostock cornea module: diversity and diagnostic implications in patients with uveitis. Ocul Immunol Inflamm. 2018;26:900-9.

33 Mahendradas P, Srinivasan T, Kawali A, Venkatesh R, Hazarika D, Patil S, et al. Floral pattern of keratic precipitates in vitreoretinal lymphoma on in vivo confocal microscopy. Ocul Immunol Inflamm. 2020:1-7.

34 Peng RM, Guo YX, Xiao GG, Lu Q, Sun BJ, Hong J. Clinical manifestations and characteristics of in vivo confocal microscopy in varicella zoster virus-related corneal endotheliitis. Ocul Immunol Inflamm. 2019;27:12709.

35 Shipton C, Hind J, Biagi J, Lyall D. Anterior segment optical coherence tomographic characterisation of keratic precipitates. Contact Lens Anterior Eye. 2020;48:4658.

36 Meyer PAR. Patterns of blood flow in episcleral vessels studied by low-dose fluorescein videoangiography. Eye. 1988;2(Pt 5):533-46.

37 Nieuwenhuizen J, Watson PG, Emmanouilidis-van der Spek K, Keunen JE, Jager MJ. The value of combining anterior segment fluorescein angiography with indocyanine green angiography in scleral inflammation. Ophthalmology. 2003;110:1653-66.
38 Pichi F, Sarraf D, Arepalli S, Lowder CY, Cunningham ET Jr, Neri P, et al. The application of optical coherence tomography angiography in uveitis and inflammatory eye diseases. Prog Retin Eye Res. 2017;59:178-201.

39 Alfawaz AM, Holland GN, Yu F, Margolis MS, Giaconi JA, Aldave AJ. Corneal endothelium in patients with anterior uveitis. Ophthalmology. 2016;123:1637-45.

40 Invernizzi A, Cozzi M, Staurenghi G. Optical coherence tomography and optical coherence tomography angiography in uveitis: a review. Clin Exp Ophthalmol. 2019;47:357-71.

41 Davis JL, Solomon D, Nussenblatt RB, Palestine AG, Chan CC. Immunocytochemical staining of vitreous cells. Indications, techniques, and results. Ophthalmology. 1992;99: 250-6.

42 Nussenblatt RB, Whitcup SM. Palestine AG: uveitis: fundamentals and clinical practice. St. Louis, MI: Mosby; 1996.

43 Pichi F, Invernizzi A, Tucker WR, Munk MR. Optical coherence tomography diagnostic signs in posterior uveitis. Prog Retin Eye Res. 2020;75:100797.

44 Nussenblatt RB, Palestine AG, Chan CC, Roberge F. Standardization of vitreal inflammatory activity in intermediate and posterior uveitis. Ophthalmology. 1985;92:467-71.

45 Davis JL, Madow B, Cornett J, Stratton R, Hess D, Porciatti V, et al. Scale for photographic grading of vitreous haze in uveitis. Am J Ophthalmol. 2010;150:637-e1.

46 Madow B, Galor A, Feuer WJ, Altaweel MM, Davis JL. Validation of a photographic vitreous haze grading technique for clinical trials in uveitis. Am J Ophthalmol. 2011;152:170e1.

47 Keane PA, Karampelas M, Sim DA, Sadda SR, Tufail A, Sen HN, et al. Objective measurement of vitreous inflammation using optical coherence tomography. Ophthalmology. 2014;121:1706-14.

48 Montesano G, Way CM, Ometto G, Ibrahim $\mathrm{H}$, Jones PR, Carmichael R, et al. Optimizing OCT acquisition parameters for assessments of vitreous haze for application in uveitis. Sci Rep. 2018;8:1648.

49 Terheyden JH, Ometto G, Montesano G, Wintergerst MWM, Langner M, Liu X, et al. Automated quantification of posterior vitreous inflammation: optical coherence tomography scan number requirements. Sci Rep. 2021;11(1):3271.

50 Passaglia CL, Arvaneh T, Greenberg E, Richards D, Madow B. Automated method of grading vitreous haze in patients with uveitis for clinical trials. Transl Vis Sci Technol. 2018;7:10.

51 Mahlberg PA, Cunha-Vaz JG, Tessler HH. Vitreous fluorophotometry in pars planitis. Am J Ophthalmol. 1983;95:189-96.

52 Häring G, Nölle B, Wiechens B. Ultrasound biomicroscopic imaging in intermediate uveitis. Br J Ophthalmol. 1998;82:625-9.
53 Tan AC, Fleckenstein M, Schmitz-Valckenberg S, Holz FG. Clinical application of multicolor imaging technology. Ophthalmologica. 2016;236:8-18.

54 Nicholson BP, Zhou M, Rostamizadeh M, Mehta P, Agrón E, Wong W, et al. Epidemiology of epiretinal membrane in a large cohort of patients with uveitis. Ophthalmology. 2014; $121: 2393-8$

55 Accorinti M, Okada AA, Smith JR, Gilardi M. Epidemiology of macular edema in uveitis. Ocul Immunol Inflamm. 2019;27:169-80.

56 Fardeau C, Champion E, Massamba N, LeHoang P. Uveitic macular edema. Eye. 2016;30: 1277-92.

57 Hunter RS, Skondra D, Papaliodis G, Sobrin L. Role of OCT in the diagnosis and management of macular edema from uveitis. Semin Ophthalmol. 2012;27:236-41.

58 Massa H, Pipis SY, Adewoyin T, Vergados A, Patra S, Panos GD. Macular edema associated with non-infectious uveitis: pathophysiology, etiology, prevalence, impact and management challenges. Clin Ophthalmol. 2019;13:1761-77.

59 Markomichelakis NN, Halkiadakis I, Pantelia E, Peponis V, Patelis A, Theodossiadis $\mathrm{P}$, et al. Patterns of macular edema in patients with uveitis: qualitative and quantitative assessment using optical coherence tomography. Ophthalmology. 2004;111:946-53.

60 Iannetti L, Accorinti M, Liverani M, Caggiano C, Abdulaziz R, Pivetti-Pezzi P. Optical coherence tomography for classification and clinical evaluation of macular edema in patients with uveitis. Ocul Immunol Inflamm. 2008; 16:155-60.

61 Munk MR, Bolz M, Huf W, Sulzbacher F, Roberts P, Simader C, et al. Morphologic and functional evaluations during development, resolution, and relapse of uveitis-associated cystoid macular edema. Philadelphia, PA: Retina; 2013. Vol. 33.

62 Pohlmann D, Vom Brocke GA, Winterhalter S, Steurer T, Thees S, Pleyer U. Dexamethasone inserts in noninfectious uveitis: a singlecenter experience. Ophthalmology. 2018;125: 1088-99.

63 Thorne JE, Sugar EA, Holbrook JT, Burke AE, Altaweel MM, Vitale AT, et al. Periocular triamcinolone vs. intravitreal triamcinolone vs. intravitreal dexamethasone implant for the treatment of uveitic macular edema: the periOcular vs. INTravitreal corticosteroids for uveitic macular edema (POINT) Trial. Ophthalmology. 2019;126:283-95.

64 Jaffe GJ, Pavesio CE. Effect of a fluocinolone acetonide insert on recurrence rates in noninfectious intermediate, posterior, or panuveitis: three-year results. Ophthalmology. 2020; 127:1395-404.

65 Jacobson MA, Polsky B, Causey D, Davis R, Tong W, O'Donnell JJ, et al., Pharmacodynamic relationship of pharmacokinetic parameters of maintenance doses of foscarnet and clinical outcome of cytomegalovirus retinitis. Antimicrob Agents Chemother. 1994; 38:1190-3. 
66 Kempen JH, Kempen JH, Altaweel MM, Drye LT, Holbrook JT, Jabs DA, et al. Benefits of systemic anti-inflammatory therapy versus fluocinolone acetonide intraocular implant for intermediate uveitis, posterior uveitis, and panuveitis: fifty-four-month results of the multicenter uveitis steroid treatment (MUST) trial and follow-up study. Ophthalmology. 2015;122:1967-75.

67 Dobner BC, Max R, Becker MD, Heinz C, Veltrup I, Heiligenhaus A, et al. A three-centre experience with adalimumab for the treatment of non-infectious uveitis. Br J Ophthalmol. 2013;97:134-8.

68 Sugar EA, Jabs DA, Altaweel MM, Lightman S, Acharya N, Vitale AT, et al. Identifying a clinically meaningful threshold for change in uveitic macular edema evaluated by optical coherence tomography. Am J Ophthalmol. 2011;152:1044-52.e5.

69 Roesel M, Heinz C, Koch JM, Heiligenhaus A Comparison of orbital floor triamcinolone acetonide and oral prednisolone for cataract surgery management in patients with noninfectious uveitis. Graefes Arch Clin Exp Ophthalmol. 2010;248:715-20.

70 Roesel M, Tappeiner C, Heinz C, Koch JM, Heiligenhaus A. Comparison between intravitreal and orbital floor triamcinolone acetonide after phacoemulsification in patients with endogenous uveitis. Am J Ophthalmol. 2009; 147:406-12.

71 Diaz-Llopis M, García-Delpech S, Salom D, Udaondo P, Hernández-Garfella M, BoschMorell F, et al. Adalimumab therapy for refractory uveitis: a pilot study. J Ocul Pharmacol Ther. 2008;24:351-61.

72 Okhravi N, Morris A, Kok HS, Menezo V, Dowler JG, Hykin PG, et al. Intraoperative use of intravitreal triamcinolone in uveitic eyes having cataract surgery: pilot study. J Cataract Refract Surg. 2007;33:1278-83.

73 Martín-Varillas JL, Calvo-Río V, Beltrán E, Sánchez-Bursón J, Mesquida M, Adán A, et al. Successful optimization of adalimumab therapy in refractory uveitis due to Behçet's disease. Ophthalmology. 2018;125:1444-51.

74 Mora P, Gonzales S, Ghirardini S, Rubino P, Orsoni JG, Gandolfi SA, et al. Perioperative prophylaxis to prevent recurrence following cataract surgery in uveitic patients: a two-centre, prospective, randomized trial. Acta Ophthalmol. 2016;94:e390-4.

75 Kempen JH, Van Natta ML, Altaweel MM, Dunn JP, Jabs DA, Lightman SL, et al. Factors predicting visual acuity outcome in intermediate, posterior, and panuveitis: the multicenter uveitis steroid treatment (MUST) trial. Am J Ophthalmol. 2015;160:1133-e9.

76 Gupta A, Ram J, Gupta A, Gupta V. Intraoperative dexamethasone implant in uveitis patients with cataract undergoing phacoemulsification. Ocul Immunol Inflamm. 2013;21: $462-7$.
77 Nguyen QD, Sadiq MA, Soliman MK, Agarwal A, Do DV, Sepah YJ. The effect of different dosing schedules of intravitreal sirolimus, a mammalian target of rapamycin (mTOR) inhibitor, in the treatment of non-infectious uveitis (An American Ophthalmological Society Thesis). Trans Am Ophthalmol Soc. 2016;114:T3

78 Fardeau C, Simon A, Rodde B, Viscogliosi F, Labalette $\mathrm{P}$, Looten $\mathrm{V}$, et al. Interferon-alpha2a and systemic corticosteroid in monotherapy in chronic uveitis: results of the randomized controlled BIRDFERON study. Am J Ophthalmol. 2017;177:182-94.

79 Markomichelakis NN, Halkiadakis I, Pantelia E, Georgalas I, Georgalas E, Chrysanthi K, et al. Course of macular edema in uveitis under medical treatment. Ocul Immunol Inflamm. 2007;15:71-9.

80 Grajewski RS, Boelke AC, Adler W, Meyer S, Caramoy A, Kirchhof B, et al. Spectral-domain optical coherence tomography findings of the macula in 500 consecutive patients with uveitis. Eye. 2016;30:1415-23.

81 Grewal DS, O’Sullivan ML, Kron M, Jaffe GJ. Association of disorganization of retinal inner layers with visual acuity in eyes with uveitic cystoid macular edema. Am J Ophthalmol. 2017;177:116-25.

82 Munk MR, Jampol LM, Simader C, Huf W, Mittermüller TJ, Jaffe GJ, et al. Differentiation of diabetic macular edema from pseudophakic cystoid macular edema by spectral-domain optical coherence tomography. Invest Ophthalmol Vis Sci. 2015;56:6724-33.

83 Dysli M, Rückert R, Munk MR. Differentiation of underlying pathologies of macular edema using spectral domain optical coherence tomography (SD-OCT). Ocul Immunol Inflamm. 2019;27:474-83.

84 Antcliff RJ, Stanford MR, Chauhan DS, Graham EM, Spalton DJ, Shilling JS, et al. Comparison between optical coherence tomography and fundus fluorescein angiography for the detection of cystoid macular edema in patients with uveitis. Ophthalmology. 2000;107: 593-9.

85 Ossewaarde-van Norel J, Camfferman LP, Rothova A. Discrepancies between fluorescein angiography and optical coherence tomography in macular edema in uveitis. Am J Ophthalmol. 2012;154:233-9.

$86 \mathrm{Kim}$ BH, Shin JY, Yu HG. Discrepancy in fluorescein angiography and optical coherence tomography findings of macular edema in intermediate uveitis. Ocul Immunol Inflamm. 2016;24:653-9.

87 Herbort CP Jr, Tugal-Tutkun I, Mantovani A, Neri P, Khairallah M, Papasavvas I. Advances and potential new developments in imaging techniques for posterior uveitis Part 2: invasive imaging methods. Eye. 2020;35:5273.

88 Kempen JH, Sugar EA, Jaffe GJ, Acharya NR, Dunn JP, Elner SG, et al. Fluorescein angiography versus optical coherence tomography for diagnosis of uveitic macular edema. Ophthalmology. 2013;120:1852-9.
89 Suhler EB, Smith JR, Wertheim MS, Lauer AK, Kurz DE, Pickard TD, et al. A prospective trial of infliximab therapy for refractory uveitis: preliminary safety and efficacy outcomes. Arch Ophthalmol. 2005;123:90312.2005

90 Zicarelli F, Mantovani A, Preziosa C, Staurenghi G. Multimodal imaging of multiple evanescent white dot syndrome: a new interpretation. Ocul Immunol Inflamm. 2019; 28:814-20.

91 Moore DB, Jaffe GJ, Asrani S. Retinal nerve fiber layer thickness measurements: uveitis, a major confounding factor. Ophthalmology. 2015;122:511-7.

92 Lee MW, Lee TH, Won YK, Shin YI, Kim JY. Characteristics of retinal layer thickness in acute anterior uveitis: an optical coherence tomography study. Acta Ophthalmol. 2020; 98:e50-5.

93 Ueno S, Kawano K, Ito Y, Ra E, Nakanishi A, Nagaya $M$, et al. Near-infrared reflectance imaging in eyes with acute zonal occult outer retinopathy. Retina. 2015;35(8): 1521-30.

94 Delori FC, Dorey CK, Staurenghi G, Arend O, Goger DG, Weiter JJ. In vivo fluorescence of the ocular fundus exhibits retinal pigment epithelium lipofuscin characteristics. Invest Ophthalmol Vis Sci. 1995;36: $718-29$.

95 Haen SP, Spaide RF. Fundus autofluorescence in multifocal choroiditis and panuveitis. Am J Ophthalmol. 2008;145:847-53.

96 Koizumi H, Pozzoni MC, Spaide RF. Fundus autofluorescence in birdshot chorioretinopathy. Ophthalmology. 2008;115:e1520.

97 Durrani K, Foster CS. Fundus autofluorescence imaging in posterior uveitis. Semin Ophthalmol. 2012;27:228-35.

98 Hashimoto H, Kishi S. Ultra-wide-field fundus autofluorescence in multiple evanescent white dot syndrome. Am J Ophthalmol. 2015;159:698-706.

99 Ometto G, Montesano G, Sadeghi Afgeh S, Lazaridis G, Liu X, Keane PA, et al. Merging information from infrared and autofluorescence fundus images for monitoring of chorioretinal atrophic lesions. Transl Vis Sci Technol. 2020;9:38.

100 Boudreault K, Schuerch K, Zhao J, Lee W, Cabral T, Yannuzzi LA, et al. Quantitative autofluorescence intensities in acute zonal occult outer retinopathy vs healthy eyes. JAMA Ophthalmol. 2017;135:1330-8.

101 Quillen DA, Davis JB, Gottlieb JL, Blodi BA, Callanan DG, Chang TS, et al. The white dot syndromes. Am J Ophthalmol. 2004;137: 538-50.

102 Teussink MM, Huis In Het Veld PI, de Vries LA, Hoyng CB, Klevering BJ, Theelen T. Multimodal imaging of the disease progression of birdshot chorioretinopathy. Acta Ophthalmol. 2016;94:815-23. 
103 Pohlmann D, Macedo S, Stübiger N, Pleyer U, Joussen AM, Winterhalter S. Multimodal imaging in birdshot retinochoroiditis. Ocul Immunol Inflamm. 2017;25: 621-32.

104 Campbell JP, Leder HA, Sepah YJ, Gan T, Dunn JP, Hatef E, et al. Wide-field retinal imaging in the management of noninfectious posterior uveitis. Am J Ophthalmol. 2012;154:908-11.e2.

105 Nicholson BP, Nigam D, Miller D, Agrón E, Dalal M, Jacobs-El N, et al. Comparison of wide-field fluorescein angiography and 9-field montage angiography in uveitis. Am J Ophthalmol. 2014;157:673-7.

106 Karampelas M, Sim DA, Chu C, Carreno E, Keane PA, Zarranz-Ventura J, et al. Quantitative analysis of peripheral vasculitis, ischemia, and vascular leakage in uveitis using ultra-widefield fluorescein angiography. Am J Ophthalmol. 2015;159:1161-e1.

107 Tripathy K, Ying H, Maldonado Cerda A, Filipowicz A, Kaya M, Seymen Z, et al. Widefield fundus fluorescein angiography features of uveitis associated with juvenile idiopathic arthritis. Ocul Immunol Inflamm. 2020:1-10.

108 Laovirojjanakul W, Acharya N, Gonzales JA. Ultra-widefield fluorescein angiography in intermediate uveitis. Ocul Immunol Inflamm. 2019;27(3):356-61.

109 Agarwal A, Afridi R, Agrawal R, Do DV, Gupta V, Nguyen QD. Multimodal imaging in retinal vasculitis. Ocul Immunol Inflamm. 2017;25:424-33.

110 Mahendradas P, Vala R, Kawali A, Akkali MC, Shetty R. Adaptive optics imaging in retinal vasculitis. Ocul Immunol Inflamm. 2018;26(5):760-6.

111 Roberts PK, Nesper PL, Onishi AC, Skondra D, Jampol LM, Fawzi AA. Characterizing photoreceptor changes in acute posterior multifocal placoid pigment epitheliopathy using adaptive optics. Retina. 2018;38:3948.

112 Khanna S, Nesper PL, Koreishi AF, Goldstein DA, Faze AA. Visualization of photoreceptors in birdshot chorioretinopathy using adaptive optics scanning laser ophthalmoscopy: a pilot study. Ocul Immunol Inflamm. 2017;25:610-20.

113 Errera MH, Laguarrigue M, Rossant F, Koch E, Chaumette C, Fardeau C, et al. High-resolution imaging of retinal vasculitis by flood illumination adaptive optics ophthalmoscopy: a follow-up study. Ocul Immunol Inflamm. 2019;28:1171-80.

114 Herbort CP, LeHoang P, Guex-Crosier Y. Schematic interpretation of indocyanine green angiography in posterior uveitis using a standard angiographic protocol. Ophthalmology. 1998;105:432-40.

115 Wolfensberger TJ, Herbort CP. Indocyanine green angiographic features in ocular sarcoidosis. Ophthalmology. 1999;106:2859.

Structural Endpoints in Uveitis
116 Pepple KL, Chu Z, Weinstein J, Munk MR, Van Gelder RN, Wang RK. Use of en face swept-source optical coherence tomography angiography in identifying choroidal flow voids in 3 patients with birdshot chorioretinopathy. JAMA Ophthalmol. 2018; 136:1288-92.

117 Tugal-Tutkun I, Herbort CP Jr, Mantovani A, Neri P, Khairallah M. Advances and potential new developments in imaging techniques for posterior uveitis. Part 1: noninvasive imaging methodsatl. Eye. 2020;35:3351.

118 Mahendradas P, Maruyama K, Mizuuchi K, Kawali A, Kitaichi N. Multimodal imaging in ocular sarcoidosis. Ocul Immunol Inflamm. 2020;28:1205-11.

119 Mehta H, Sim DA, Keane PA, Zarranz-Ventura J, Gallagher K, Egan CA, et al. Structural changes of the choroid in sarcoid- and tuberculosis-related granulomatous uveitis. Eye. 2015;29:1060-8.

120 Invernizzi A, Mapelli C, Viola F, Cigada M, Cimino L, Ratiglia R, et al. Choroidal granulomas visualized by enhanced depth imaging optical coherence tomography. Retina. 2015;35:525-31.

121 Yan H, Li J, Zhang J, Yang L. Retinal and choroidal thickness in patients with vveitis. Ocul Immunol Inflamm. 2017;25:202-9.

122 Liu S, Du L, Zhou Q, Zhang Q, Hu K, Qi J, et al. The choroidal vascularity index decreases and choroidal thickness increases in Vogt-Koyanagi-Harada disease patients during a recurrent anterior uveitis attack. Ocul Immunol Inflamm. 2018;26:1237-43.

123 Maehara H, Sekiryu T, Sugano Y, Maruko I. Choroidal thickness changes in acute zonal occult outer retinopathy. Retina. 2019; 39(1):202-9.

124 Forte R, Aptel F, Thia-Soui-Tchong K, Salmon L, Mailhac A, Bouillet L, et al. Choroidal thickness in birdshot retinochoroiditis over a 2-year period. Ophthalmologica. 2019;241:49-55.

125 Chee SP, Chan SN, Jap A. Comparison of enhanced depth imaging and swept source optical coherence tomography in assessment of choroidal thickness in Vogt-Koyanagi-Harada disease. Ocul Immunol Inflamm. 2017;25:528-32.

126 Moharana B, Bansal R, Singh R, Sharma A, Gupta V, Gupta A. Enhanced depth imaging by high-resolution spectral domain optical coherence tomography in tubercular multifocal serpiginoid choroiditis. Ocul Immunol Inflamm. 2019;27:781-7.

127 Agrawal R, Salman M, Tan KA, Karampelas M, Sim DA, Keane PA, et al. Choroidal vascularity index (CVI): a novel optical coherence tomography parameter for monitoring patients with panuveitis? PLoS one. 2016; 11:e0146344.

128 Pohlmann D, Winterhalter S, Pleyer U. White dot syndromes: principles, diagnostics, and treatment]. Ophthalmologe. 2019; 116:1235-56.
129 Wintergerst MWM, Pfau M, Müller PL, Berger M, de Sisternes L, Holz FG, et al. Optical coherence tomography angiography in intermediate uveitis. Am J Ophthalmol. 2018;194:35-45.

130 Tang W, Guo J, Liu W, Xu G. Quantitative analysis of retinal and choriocapillary vascular density of multiple evanescent white dot syndrome by optical coherence tomography angiography. Graefes Arch Clin Exp Ophthalmol. 2020;258:1697-707.

131 Chu Z, Weinstein JE, Wang RK, Pepple KL. Quantitative analysis of the choriocapillaris in uveitis using en face swept source optical coherence tomography angiography. Am J Ophthalmol. 2020.

132 Abu el-Asrar AM, Tabbara KF. Retinal vasculitis. Curr Opin Ophthalmol. 1997;8:68-79.

133 Matsuo T, Sato Y, Shiraga F, Shiragami C, Tsuchida Y. Choroidal abnormalities in Behçet disease observed by simultaneous indocyanine green and fluorescein angiography with scanning laser ophthalmoscopy. Ophthalmology. 1999;106:295-300.

134 Walton RC, Ashmore ED. Retinal vasculitis. Curr Opin Ophthalmol. 2003;14:413-9.

135 Tugal-Tutkun I, Ozdal PC, Oray M, Onal S. Review for diagnostics of the year: multimodal imaging in behcet uveitis. Ocul Immunol Inflamm. 2017;25:7-19.

136 Thomas AS, Redd T, Campbell JP, Palejwala NV, Baynham JT, Suhler EB, et al. The impact and implication of peripheral vascular leakage on ultra-widefield fluorescein angiography in uveitis. Ocul Immunol Inflamm. 2019;27:349-55.

137 Datoo O'Keefe GA, Rao N. Retinal vasculitis: a framework and proposal for a classification system. Survey Ophthalmol. 2020;66 5467.

138 Kaburaki T, Fukunaga H, Tanaka R, Nakahara $\mathrm{H}$, Kawashima $\mathrm{H}$, Shirahama $\mathrm{S}$, et al. Retinal vascular inflammatory and occlusive changes in infectious and non-infectious uveitis. Jpn J Ophthalmol. 2020;64: 150-9.

139 Kim AY, Rodger DC, Shahidzadeh A, Chu Z, Koulisis N, Burkemper B, et al. Quantifying retinal microvascular changes in uveitis using spectral-domain optical coherence tomography angiography. Am J Ophthalmol. 2016;171:101-12.

140 Waizel M, Todorova MG, Terrada C, LeHoang P, Massamba N, Bodaghi B. Superficial and deep retinal foveal avascular zone OCTA findings of non-infectious anterior and posterior uveitis. Graefes Arch Clin Exp Ophthalmol. 2018;256:197784.

141 Goker YS, Ozdal PC, Erol YO, Kiziltoprak H, Karatepe MS. Evaluation of radial peripapillary capillary density in patients with Fuchs uveitis syndrome. Graefes Arch Clin Exp Ophthalmol. 2019;257:2735-42.

142 Graham EM, Stanford MR, Shilling IS, Sanders MD. Neovascularisation associated with posterior uveitis. $\mathrm{Br} \mathrm{J}$ Ophthalmol. 1987;71:826-33. 
143 Parodi MB, Iacono P, La Spina C, Knutsson KA, Mansour A, Arevalo JF, et al. Intravitreal bevacizumab for choroidal neovascularisation in serpiginous choroiditis. $\mathrm{Br} \mathrm{J}$ Ophthalmol. 2014;98:519-22.

144 Cheng L, Chen X, Weng S, Mao L, Gong Y, Yu S, et al. Spectral-domain optical coherence tomography angiography findings in multifocal choroiditis with active lesions. Am J Ophthalmol. 2016;169:145-61.

145 Yee HY, Keane PA, Ho SL, Agrawal R. Optical coherence tomography angiography of choroidal neovascularization associated with tuberculous serpiginous-like choroiditis. Ocul Immunol Inflamm. 2016;24:699701 .

146 Shorb SR, Irvine AR, Kimura SJ. Optic disk neovascularization associated with chronic uveitis. Am J Ophthalmol. 1976;82:175-8.

147 Brucker AJ, Deglin EA, Bene C, Hoffman ME. Subretinal choroidal neovascularization in birdshot retinochoroidopathy. Am J Ophthalmol. 1985;99:40-4.

148 Dolz-Marco R, Fine HF, Freund KB. How to differentiate myopic choroidal neovascularization, idiopathic multifocal choroiditis, and punctate inner choroidopathy using clinical and multimodal imaging findings. Ophthalmic Surg Lasers Imaging Retina. 2017;48:196-201.

149 Levison AL, Baynes KM, Lowder CY, Kaiser PK, Srivastava SK. Choroidal neovascularisation on optical coherence tomography angiography in punctate inner choroidopathy and multifocal choroiditis. Br J Ophthalmol. 2017;101:616-22.

150 Astroz P, Miere A, Mrejen S, Sekfali R, Souied EH, Jung C, et al. Optical coherence tomography angiography to distinguish choroidal neovascularization from macular inflammatorylesions in multifocal choroiditis. Retina. 2018;38(2):299-309.

151 Amer R, Priel E, Kramer M. Spectral-domain optical coherence tomographic features of choroidal neovascular membranes in multifocal choroiditis and punctate inner choroidopathy. Graefes Arch Clin Exp Ophthalmol. 2015;253:949-57.

152 Pohlmann D, Pleyer U, Joussen AM, Winterhalter S. Optical coherence tomography angiography in comparison with other multimodal imaging techniques in punctate inner choroidopathy. Br J Ophthalmol. 2019; 103:60-6.

153 Nozaki M, Hamada S, Kimura M, Yoshida $\mathrm{M}$, Ogura $\mathrm{Y}$. Value of OCT angiography in the diagnosis of choroidal neovascularization complicating multiple evanescence white dot syndrome. Ophthalmic Surg Lasers Imaging Retina. 2016;47:580-4.

154 Aggarwal K, Agarwal A, Sharma A, Sharma K, Gupta V. Detection of Type 1 choroidal neovascular membranes using optical coherence tomography angiography in tubercular posterior uveitis. Retina. 2019;39(8): 1595-606.
155 Pohlmann D, Pleyer U, Joussen AM, Winterhalter S. Immunosuppressants and/or antivascular endothelial growth factor inhibitors in punctate inner choroidopathy? Follow-up results with optical coherence tomography angiography. $\mathrm{Br} \mathrm{J}$ Ophthalmol. 2019;103:1152-7.

156 Heiligenhaus A, Foeldvari I, Edelsten C, Smith JR, Saurenmann RK, Bodaghi B, et al. Proposed outcome measures for prospective clinical trials in juvenile idiopathic arthritis-associated uveitis: a consensus effort from the multinational interdisciplinary working group for uveitis in childhood. Arthritis Care Res. 2012;64:1365-72.

157 Herbort CP Jr, Tugal-Tutkun I, Neri P, Pavésio C, Onal S, LeHoang P. Failure to integrate quantitative measurement methods of ocular inflammation hampers clinical practice and trials on new therapies for posterior uveitis. J Ocul Pharmacol Ther. 2017; 33:263-77.

158 Tallouzi MO, Mathers JM, Moore DJ, Murray PI, Bucknall N, Blazeby JM, et al. COSUMO: study protocol for the development of a core outcome set for efficacy and effectiveness trials in posterior segment-involving uveitis. Trials. 2017;18:576.

159 Mastrangelo G, Foeldvari I, Anton J, Simonini G. Defining outcome measures in juvenile idiopathic arthritis associated uveitis by a systematic review analysis: do we need a consensus? Pediatr Rheumatol Online J. 2019;17:40.

160 Tallouzi MO, Mathers JM, Moore DJ, Bucknall N, Calvert MJ, Murray PI, et al. Development of a core outcome set for clinical trials in non-infectious uveitis of the posterior segment. Ophthalmology. 2021.

161 Food and Drug Administration, National Institutes of Health Biomarker Working Group. BEST (Biomarkers, endpointS, and other tools) resource. Silver Spring (MD), Bethesda (MD): National Institutes of Health (US); 2016

162 Pocock SJ, Stone GW. The primary outcome fails: what next? N Engl J Med. 2016; 375:861-70

163 FitzGerald GA. Measure for measure: biomarker standards and transparency. Sci Transl Med. 2016;8:343fs10.

164 Robb MA, McInnes PM, Califf RM. Biomarkers and surrogate endpoints: developing common terminology and definitions. JAMA. 2016;315:1107-8.

165 Wickstrom K, Moseley J. Biomarkers and surrogate endpoints in drug development: a European regulatory view. Invest Ophthalmol Visual Sci. 2017;58:BIO27-33.

166 Jaffe GJ, Dick AD, Brézin AP, Nguyen QD, Thorne JE, Kestelyn P, et al. Adalimumab in patients with active noninfectious uveitis. $\mathrm{N}$ Engl J Med. 2016;375:932-43.
167 Solebo AL, Barry RJ, Keane PA, Rahi JS, Denniston AK. Under-utilisation of reproducible, child appropriate or patient reported outcome measures in childhood uveitis interventional research. Orphanet J Rare Dis. 2019;14:125.

168 Venkat AG, Sharma S. Automated measurement of leakage on wide-field angiography in the assessment of retinal vasculitis. I Ophthalmic Inflamm Infect. 2020;10:4.

169 Haasnoot AJ, Vernie LA, Rothova A, V D Doe P, Los LI, Schalij-Delfos NE, et al. Impact of juvenile idiopathic arthritis associated uveitis in early adulthood. PLoS one. 2016;11:e0164312.

170 Pockar S, Globocnik Petrovic M, Peterlin B, Vidovic Valentincic N. MiRNA as biomarker for uveitis: a systematic review of the literature. Gene. 2019;696:162-75.

171 Thieme C, Schlickeiser S, Metzner S, Dames $\mathrm{C}$, Pleyer U. Immune mediator profile in aqueous humor differs in patients with primary acquired ocular toxoplasmosis and recurrent acute ocular toxoplasmosis. Mediators Inflamm. 2019;2019:9356728.

172 Haasnoot AJW, Kuiper JJW, de Boer JH Predicting uveitis in juvenile idiopathic arthritis: from biomarkers to clinical practice. Expert Rev Clin Immunol. 2019;15:657-66.

173 Cordoba G, Schwartz L, Woloshin S, Bae H Gøtzsche PC. Definition, reporting, and interpretation of composite outcomes in clinical trials: systematic review. BMJ. 2010;341: c3920.

174 Pocock SJ, Stone GW. The primary outcome is positive: is that good enough? $\mathrm{N}$ Engl J Med. 2016;375:971-9.

175 Invernizzi A, Marchi S, Aldigeri R, Mastrofilippo V, Viscogliosi F, Soldani A, et al. Objective quantification of anterior chamber inflammation: measuring cells and flare by anterior segment optical coherence tomography. Ophthalmology. 2017;124:1670-7.

176 Munk MR, Kiss CG, Steiner I, Sulzbacher F, Roberts P, Kroh M, et al. Systematic correlation of morphologic alterations and retinal function in eyes with uveitis-associated cystoid macular oedema during development, resolution and relapse. Br J Ophthalmol. 2013;97:1289-96.

177 Kim YN, Park JH, Tchah H. Quantitative analysis of lens nuclear density using optical coherence tomography (OCT) with a liquid optics interface: correlation between OCT images and LOCS III grading. J Ophthalmol. 2016;2016:3025413.

178 Panthier C, de Wazieres A, Rouger H, Mo$\operatorname{ran}$ S, Saad A, Gatinel D. Average lens density quantification with swept-source optical coherence tomography: optimized, automated cataract grading technique. J Cataract Refract Surg. 2019;45:1746-52.

179 Ohara K, Okubo A, Miyazawa A, Miyamoto T, Sasaki H, Oshima F. Aqueous flare and cell measurement using laser in endogenous uveitis patients. Jpn J Ophthalmol. 1989;33: 265-70. 
180 Chiou AG, Florakis GJ, Herbort CP. Correlation between anterior chamber IgG/albumin concentrations and laser flare photometry in eyes with endogenous uveitis. Ophthalmologica. 1998;212:275-7.

181 Shah SM, Spalton DJ, Taylor JC. Correlations between laser flare measurements and anterior chamber protein concentrations. Invest Ophthalmol Vis Sci. 1992;33:287884.

182 Yang PZ, Wang H, Huang XK, Zhou HY, Zhang Z, Chu LQ, et al. Quantitative determination of aqueous flare and cells in the eyes of patients with inflammation of anterior uvea. Zhonghua Yan Ke Za Zhi. 2004; 40:510-3.

183 Fang W, Zhou H, Yang P, Huang X, Wang L, Kijlstra A. Aqueous flare and cells in Fuchs syndrome. Eye. 2009;23:79-84.

184 Konstantopoulou K, Del'Omo R, Morley AM, Karagiannis D, Bunce C, Pavesio C. A comparative study between clinical grading of anterior chamber flare and flare reading using the Kowa laser flare meter. Int Ophthalmol. 2015;35:629-33.

185 Bansal R, Basu S, Gupta A, Rao N, Invernizzi A, Kramer M. Imaging in tuberculosis-associated uveitis. Indian J Ophthalmol. 2017; 65:264-70.

186 Setälä K. Corneal endothelial cell density in iridocyclitis. Acta Ophthalmol. 1979;57: 277-86.
187 Olsen T. Changes in the corneal endothelium after acute anterior uveitis as seen with the specular microscope. Acta Ophthalmol. 1980;58:250-6.

188 Szepessy Z, Tóth G, Barsi Á, Kránitz K, Nagy ZZ. Anterior segment characteristics of fuchs uveitis syndrome. Ocul Immunol Inflamm. 2016;24:594-8.

189 Jap A, Chee SP. Viral anterior uveitis. Curr Opin Ophthalmol. 2011;22:483.

190 Tugal-Tutkun I. Pediatric uveitis. J Ophthalmic Vis Res. 2011;6(4):259-69.

191 Tugal-Tutkun I, Otük-Yasar B, Altinkurt E. Clinical features and prognosis of herpetic anterior uveitis: a retrospective study of 111 cases. Int Ophthalmol. 2010;30:559-65.

192 Tugal-Tutkun I, Onal S, Ozyazgan Y, Soylu M, Akman M. Validity and agreement of uveitis experts in interpretation of ocular photographs for diagnosis of Behçet uveitis. Ocul Immunol Inflamm. 2014;22:461-8.

193 Whitcup SM, Csaky KG, Podgor MJ, Chew EY, Perry CH, Nussenblatt RB. A randomized, masked, cross-over trial of acetazolamide for cystoid macular edema in patients with uveitis. Ophthalmology. 1996; 103: 1054-3; discussion 106253.
194 Nussenblatt RB, Palestine AG, Chan CC, Stevens G Jr, Mellow SD, Green SB. Randomized, double-masked study of cyclosporine compared to prednisolone in the treatment of endogenous uveitis. Am J Ophthalmol. 1991;112:138-46.

195 Ciardella AP, Prall FR, Borodoker N, Cunningham ET Jr. Imaging techniques for posterior uveitis. Curr Opin Ophthalmol. 2004; 15:519-30.

196 Tran VT, LeHoang P, Herbort CP. Value of high-frequency ultrasound biomicroscopy in uveitis. Eye. 2001;15:23-30.

197 Peizeng Y, Qianli M, Xiangkun H, Hongyan Z, Li W, Kijlstra A. Longitudinal study of anterior segment inflammation by ultrasound biomicroscopy in patients with acute anterior uveitis. Acta Ophthalmol. 2009;87: 211-5.

198 Yang P, Fang W, Jin H, Li B, Chen X, Kijlstra A. Clinical features of Chinese patients with Fuchs' syndrome. Ophthalmology. 2006; 113:473-80.

199 Lam DL, Axtelle J, Rath S, Dyer A, Harrison B, Rogers C, et al. A rayleigh scatter-based ocular flare analysis meter for flare photometry of the anterior chamber. Transl Vis Sci Technol. 2015;4:7-.

200 Nanavaty MA, Stanford MR, Sharma R, Dhital A, Spalton DJ, Marshall J. Use of the double-pass technique to quantify ocular scatter in patients with uveitis: a pilot study. Ophthalmologica. 2011;225:61-6. 